\title{
Article
}

\section{Effects of crystallinity of ZSM-5 zeolite on para-selective tert-butylation of ethylbenzene}

\author{
PUSHPARAJ Hemalatha a, MANI Ganesh a, MUTHIAHPILLAI Palanichamya, \\ VELAYUTHAM Murugesan ${ }^{b}$, PARK Yong-Ki c, CHOI Won Choon c , JANG Hyun Tae a,* \\ a Department of Chemical Engineering, Hanseo University, Seosan-si 356 706, South Korea \\ b Department of Chemistry, Anna University, Chennai 600 025, India \\ c Green Chemistry Research Division, Korea Research Institute of Chemical Technology, Jang-dong 100, Daejeon 305 600, South Korea
}

\section{A R T I C L E I N F O}

Article history:

Received 18 July 2012

Accepted 13 November 2012

Published 20 February 2013

\section{Keywords:}

ZSM-5

Fluoride medium

$P$-selectivity

Ethylbenzene

Tert-butylation

Zeolite

\begin{abstract}
A B S T R A C T
Highly crystalline ZSM-5 zeolites are important for para-selective alkylation of alkyl aromatics, because they carry few external acid sites for isomerization of $p$-dialkyl products. Such zeolites $(\mathrm{Si} / \mathrm{Al}=25,50$, and 75$)$ were synthesized in a fluoride medium between $\mathrm{pH} 4$ and 6 . Their crystallinities, crystal sizes, and surface areas were higher than those of a commercial ZSM-5 zeolite. Their para selectivities in alkylation were tested for vapor-phase tert-butylation of ethylbenzene between 200 and $400{ }^{\circ} \mathrm{C}$. As expected, all the catalysts showed more than $90 \%$ para selectivity. At $300{ }^{\circ} \mathrm{C}$, ethylbenzene conversion decreased in the order ZSM-5(25, commercial) $>$ ZSM-5(25) > ZSM-5(50) $>$ ZSM-5(75). The catalysts had weak, medium, and strong acid sites, but all the acid sites of ZSM-5(75) were weaker than those of ZSM-5(25) and ZSM-5(50). The high activity of commercial ZSM-5 was caused by its strong acid sites being stronger than those of the synthesized zeolites. Although the activity of the commercial catalyst was higher than those of the present catalysts, the selectivity for 4-t-butylethylbenzene (4-t-BEB) was low. The optimum feed ratio (ethylbenzene:t-butyl alcohol) was $2: 1$ and the feed rate was $1.65 \mathrm{~h}^{-1}$ for high ethylbenzene conversion and $4-t$-BEB selectivity. Time-on-stream studies showed slow catalyst deactivation. Highly crystalline ZSM-5 zeolites are therefore better than a commercial zeolite for para-selective alkylation of alkyl aromatics. They do not require much post-modification for high para selectivity. A fluoride medium is therefore better than an alkaline medium for obtaining highly crystalline para-selective ZSM-5 zeolites.
\end{abstract}

(C) 2013, Dalian Institute of Chemical Physics, Chinese Academy of Sciences. Published by Elsevier B.V. All rights reserved.

\section{Introduction}

The alkylation of alkyl aromatics to dialkylated compounds via simple alkylation, trans alkylation, or disproportionation is commercially important [1], because of the uses of the dialkyl products; for example, $p$-xylene is used to obtain terephthalic acid, a monomer for terylene [2,3]; $p$-ethyltoluene is used to produce $p$-methylstyrene, the monomer for poly $(p$-methylstyrene) $[4,5] ; p$-diethylbenzene is used to produce divinylbenzene, a monomer for cross-linked polystyrene [6]; and other $p$-alkylated ethylbenzenes are used to produce $p$-alkylated styrenes, the monomers for poly( $p$-alkylated styrenes), which have high glass-transition temperatures $\left(T_{\mathrm{g}}\right)$ compared with polystyrene [7]. Zeolites have been widely used

\footnotetext{
* Corresponding author. Tel.: +82-41-6601423; Fax: +82-41-6881343; E-mail: htjang@hanseo.ac.kr

This work was supported by grants from Korea CCS R\&D Centre, funded by the Ministry of Education, Science and Technology of the Korean Government.
}

DOI: 10.1016/S1872-2067(11)60482-8 | http://www.sciencedirect.com/science/journal/18722067 | Chin. J. Catal., Vol. 34, No. 2, February 2013 
as catalysts for alkylation of alkyl aromatics [8]. Dialkylation was reported over $\mathrm{X}$ and $\mathrm{Y}$ zeolites partly loaded with rare earths [9]. In many alkylation processes, the meta isomer, rather than the ortho and para isomers, is formed, but $p a-$ $r a$-selective alkylation has been attempted in most alkylations. para-Selective alkylation was first demonstrated by Mobil researchers for the production of $p$-xylene $[10,11]$.

Generally, in an alkylation, alkyl cations attack the 2-, 4-, and 6-positions of alkyl aromatics, as alkyl groups are ortho- and para-directing. If the alkyl groups are bulky, para substitution becomes predominant over ortho substitution. However, at high temperatures, 1,4-dialkyl products isomerize to 1,3-dialkyl products on the Brönsted acid sites of zeolites. Since isomerization requires a large amount of space, it is more prevalent in large-pore zeolites. External acid sites also contribute to isomerization and such sites arise as a result of low crystallinity. Hence, for para-selective alkylation, a highly crystalline, medium-pore ZSM-5 zeolite is a suitable choice. It can provide selective constrained access to, and egress from, the intra-crystalline free spaces to molecules of size less than the pore size of about $0.55 \mathrm{~nm}$. It is a unique characteristic of ZSM-5 to exhibit para selectivity.

For commercial ZSM-5 zeolites, various modification methods have been reported [12-14]. In all of these methods, passivation of the external surface acidity and narrowing of the pore openings [15] were used to enhance the para selectivity. However, such modifications drastically reduced conversion. In this context, ZSM-5 zeolites synthesized in fluoride media are convenient substitutes for commercial zeolites. Such zeolites are large crystals, have high crystallinity, and are defect-free, with high surface areas [16-18]. High crystallinity and large crystal size enhance para selectivity, and an inverse relationship between the rate of isomerization and crystal radius has been reported in the literature [19-21].

In this study, tert-butylation of ethylbenzene was carried out in the vapor phase over ZSM-5 catalysts synthesized in a fluoride medium. 4-tert-Butylation of ethylbenzene is important as its dehydrogenated product, 4-t-butylvinylbenzene (4-t-BVB), is an important monomer for the commercial production of poly(4-t-butylstyrene), which has a high $T_{\mathrm{g}}$ value. The same reaction was also studied over Al-MCM-41, and high para selectivity was reported [22]. Bidart et al. [23] studied tert-butylation of ethylbenzene over FeY zeolite and reported mainly monoalkylation. There have been no reports of the same reaction over ZSM-5 synthesized in a fluoride medium.

A major stumbling block in the synthesis of ZSM-5 in a fluoride medium is the reduced amount of aluminum transport from the gel to the framework as a result of the formation of $\mathrm{AlF}_{X}$ species. In our laboratory, this problem was solved by using phosphate as a co-complexant to fluoride. Syntheses of ZSM-5 were also carried out using different silicon sources to select the best source for high crystallinity.

\section{Experimental}

\subsection{Materials}

Tetraethyl orthosilicate (TEOS; 98\%), tetrapropylammonium bromide (98\%), aluminum sulfate octadecahydrate (98\%), ammonia (28\%), ammonium fluoride (99\%), and sodium aluminate (50-56\% $\mathrm{Al}_{2} \mathrm{O}_{3}$ ) (all obtained from Aldrich), as well as orthophosphoric acid (85\%) and hydrofluoric acid (48\%) (both obtained from Merck), were used in the syntheses. LUDOX-ammonium-stabilized colloidal silica (AS silica; $40 \mathrm{wt} \%$ suspension in water), LUDOX-sodium-stabilized colloidal silica (HS silica; $40 \mathrm{wt} \%$ suspension in water), fumed silica, and sodium silicate $\left(\sim 26.5 \% \mathrm{SiO}_{2}\right)$ (all obtained from Aldrich) were used as silicon sources in the syntheses. Potassium hydroxide (90\%; Aldrich) was used in potentiometric titrations. The chemicals used in the catalytic reactions, i.e., ethylbenzene and $t$-butyl alcohol, were of Merck grade.

\subsection{Optimization of fluoride content for ZSM-5 syntheses}

The following gel composition was used [16] for the ZSM-5 syntheses in a fluoride medium: $0.07 \mathrm{C}_{12} \mathrm{H}_{28} \mathrm{NBr}: 1.0 \mathrm{SiO}_{2}: 0.006$ $\mathrm{Al}_{2} \mathrm{O}_{3}: x \mathrm{NH}_{4} \mathrm{~F}: 80 \mathrm{H}_{2} \mathrm{O}$.

The syntheses were carried out initially with TEOS and sodium aluminate as the sources for silicon and aluminum, respectively. Tetrapropylammonium bromide was used as a structure-directing template. To optimize the fluoride content for the syntheses, the $\mathrm{F} / \mathrm{Si}$ ratio was altered using $\mathrm{NH}_{4} \mathrm{~F}$; the weights are given in Table 1.

In a typical synthesis, sodium aluminate $(0.022 \mathrm{~g})$, an appropriate amount of ammonium fluoride, tetrapropylammonium bromide $(0.462 \mathrm{~g})$, and water $(35 \mathrm{~g})$ were mixed in a 100 $\mathrm{ml}$ beaker and stirred for $5 \mathrm{~h}$. TEOS (5.16 g) was added drop-wise. Stirring was continued for $3 \mathrm{~h}$. Finally, the $\mathrm{pH}$ of the mixture was reduced to 7.0 by adding two or three drops of hydrofluoric acid, and stirring was continued for $1 \mathrm{~h}$. The resulting gel was autoclaved and hydrothermal crystallization was carried out at $170{ }^{\circ} \mathrm{C}$ for $5 \mathrm{~d}$ in a static oven. The crystallized product was recovered by filtration, washed repeatedly with water, dried at $110{ }^{\circ} \mathrm{C}$ in the oven for $12 \mathrm{~h}$, and calcined at $650^{\circ} \mathrm{C}$ in air for $8 \mathrm{~h}$.

\subsection{Syntheses of ZSM-5 in fluoride medium with phosphate}

Sodium aluminate was replaced by aluminum sulfate. Phosphate was used as well as fluoride. Tetrapropylammonium bromide was used as a structure-directing agent and the gel composition was as follows: $0.07 \mathrm{C}_{12} \mathrm{H}_{28} \mathrm{NBr}: 1 \quad \mathrm{SiO}_{2}: 0.02$ $\mathrm{Al}_{2} \mathrm{O}_{3}: 1.3 \mathrm{NH}_{4} \mathrm{~F}: 0.02 \mathrm{P}_{2} \mathrm{O}_{5}: 80 \mathrm{H}_{2} \mathrm{O}$.

In a typical synthesis, aluminum sulfate $(0.330 \mathrm{~g})$, orthophosphoric acid (0.056 g), tetrapropylammonium bromide

Table 1

Weights of $\mathrm{NH}_{4} \mathrm{~F}$ used in ZSM-5 syntheses.

\begin{tabular}{cc}
\hline $\mathrm{F} /$ Si ratio & Weight of $\mathrm{NH}_{4} \mathrm{~F}(\mathrm{~g})$ \\
\hline 0.3 & 0.27 \\
0.6 & 0.54 \\
1.0 & 0.90 \\
1.3 & 1.17 \\
1.6 & 1.44 \\
2.0 & 1.80 \\
\hline
\end{tabular}


(0.462 g), and water were mixed in a $100 \mathrm{ml}$ beaker and stirred. Ammonium fluoride (1.17 g) was then added to the mixture. TEOS (5.16 g) was added and stirring was continued for $3 \mathrm{~h}$. The resulting gel was transferred to a Teflon-lined stainless-steel autoclave and hydrothermal crystallization was carried out at $170{ }^{\circ} \mathrm{C}$ for $5 \mathrm{~d}$ in a static oven. The crystallized product was recovered by filtration, dried at $110{ }^{\circ} \mathrm{C}$ for $12 \mathrm{~h}$, and calcined at $650{ }^{\circ} \mathrm{C}$ in air for $8 \mathrm{~h}$. The same procedure was repeated with appropriate quantities of aluminum sulfate to obtain ZSM-5 with $\mathrm{Si} / \mathrm{Al}=50$ and 75.

\subsection{Syntheses of ZSM-5 in fluoride medium with different silicon sources}

Syntheses of ZSM-5 in a fluoride medium were performed using different sources of silicon (TEOS, sodium silicate, AS silica, HS silica, and fumed silica). The following gel composition was used: $0.07 \quad \mathrm{C}_{12} \mathrm{H}_{28} \mathrm{NBr}: 1.0 \quad \mathrm{SiO}_{2}: 0.02 \quad \mathrm{Al}_{2} \mathrm{O}_{3}: 1.3$ $\mathrm{NH}_{4} \mathrm{~F}: 0.02 \mathrm{P}_{2} \mathrm{O}_{5}: 80 \mathrm{H}_{2} \mathrm{O}$.

In a typical procedure, aluminum sulfate $(0.330 \mathrm{~g})$, orthophosphoric acid (0.056 g), tetrapropylammonium bromide ( $0.462 \mathrm{~g}$ ), and water ( $35 \mathrm{~g}$ ) were mixed in a $100 \mathrm{ml}$ beaker and stirred for $2 \mathrm{~h}$. Ammonia (1:1) was added to give a faint permanent precipitate. After $30 \mathrm{~min}$ of stirring, ammonium fluoride (1.17 g) was added. After $5 \mathrm{~h}$ of stirring, an appropriate amount of silica source was added and stirring was continued for another $5 \mathrm{~h}$. The resulting gel was transferred to a Teflon-lined stainless-steel autoclave, and hydrothermal crystallization was carried out at $170{ }^{\circ} \mathrm{C}$ for $5 \mathrm{~d}$ in a static oven. The crystallized product was recovered by filtration, dried in an oven at $110{ }^{\circ} \mathrm{C}$ for $12 \mathrm{~h}$, and calcined at $650^{\circ} \mathrm{C}$ in air for $8 \mathrm{~h}$.

\subsection{Potentiometric titrations}

To establish complexation between phosphate and $\mathrm{Al}^{3+}$ during the ZSM-5 synthesis, potentiometric titrations were carried out. Potentiometric titrations of orthophosphoric acid (0.02 mol/L) versus potassium hydroxide $(0.6 \mathrm{~mol} / \mathrm{L})$, and orthophosphoric acid plus $\mathrm{Al}^{3+}(0.0475 \mathrm{~mol} / \mathrm{L})$ versus potassium hydroxide, were carried out using a $\mathrm{pH}$ meter (Toshniwal) provided with a combined glass electrode. The titrations were carried out in a double-walled $100 \mathrm{ml}$ beaker provided with an inlet and an outlet for water circulation. The temperature was maintained at $30{ }^{\circ} \mathrm{C}$, with an ionic strength of 0.5 $\mathrm{mol} / \mathrm{L}$. The equilibrium $\mathrm{pH}$ was measured for each addition of potassium hydroxide. The measured $\mathrm{pH}$ was plotted against the volume of alkali added to establish complex formation between phosphate and $\mathrm{Al}^{3+}$.

\subsection{Catalyst characterization}

The synthesized products were identified and their crystallinities were determined by powder X-ray diffraction (XRD) analysis. The XRD patterns were acquired on a PANalytical X'pert PRO diffractometer equipped with a $\mathrm{Cu} K_{\alpha}(0.154 \mathrm{~nm})$ radiation source and a liquid-cooled germanium solid-state detector. The samples were scanned from $5^{\circ}$ to $40^{\circ}(2 \theta)$ in steps of $0.002 \mathrm{~nm}$, with a count time of $5 \mathrm{~s}$ at each point. For the crystallinity calculations, the intensities of the peaks from $(-101),(011),(051)$, and $(-501)$ were compared with those from a commercial catalyst. The specific surface areas of the samples were measured by nitrogen adsorption at $-196{ }^{\circ} \mathrm{C}$ using a Belsorp Mini II sorption analyzer. Prior to measurements, the samples were heated for $4 \mathrm{~h}$ in vacuum at $400 \stackrel{\circ}{\circ}$. The surface areas were determined by the Brunauer-Emmett-Teller (BET) method. The morphologies and size changes of the prepared zeolite samples were studied using scanning electron microscopy (SEM; JEOL JSM 5600). The Si/Al ratios of the samples were determined using an energy-dispersive X-ray (EDS) analyzer in the SEM chamber.

Temperature-programmed desorption of ammonia ( $\mathrm{NH}_{3}$-TPD) was performed using a BELCAT-M catalyst analyzer equipped with a thermal conductivity detector. The catalyst sample $(0.2 \mathrm{~g})$ was placed in the microreactor and treated at $430{ }^{\circ} \mathrm{C}$ for $3 \mathrm{~h}$ under a He flow, followed by sorption of dry ammonia at $100{ }^{\circ} \mathrm{C}$ in a static system for $90 \mathrm{~min}$ and $1.5 \mathrm{bar}$ ammonia pressure. Stripping was then performed for $40 \mathrm{~min}$ at $100{ }^{\circ} \mathrm{C}$ under a He flow. In this way, weakly physically adsorbed ammonia in the sample was avoided. Desorption of ammonia was carried out at a rate of $10^{\circ} \mathrm{C} / \mathrm{min}$ from $100{ }^{\circ} \mathrm{C}$ up to $650{ }^{\circ} \mathrm{C}$ under an He flow (50 $\mathrm{ml} / \mathrm{min})$.

Solid-state nuclear magnetic resonance (NMR) spectra of ZSM-5 were obtained under magic-angle spinning (MAS) conditions, at ambient temperature, on a Bruker MSL 500 spectrometer. The ${ }^{27} \mathrm{Al}$ MAS-NMR spectra were recorded at a resonance frequency of $130.32 \mathrm{MHz}$, with short $2.1 \mu$ s pulse and a recycle delay of $0.1 \mathrm{~s}$. The typical rotational frequency was ca. $10 \mathrm{kHz}$, using a zirconia rotor of diameter $4 \mathrm{~mm}$, and 12500 scans were necessary to obtain a well-resolved spectrum. ${ }^{27} \mathrm{Al}$ chemical shifts were reported in relation to a liquid solution of aluminum nitrate. ${ }^{29} \mathrm{Si}$ MAS-NMR spectra were recorded at a resonance frequency of $99.361 \mathrm{MHz}$ on a Bruker MSL 500 spectrometer, with a short pulse of $4 \mu \mathrm{s}$, a recycle delay of $30 \mathrm{~s}$, and 2500 scans. The typical rotational frequency was about 4.5 $\mathrm{kHz}$, using a zirconia rotor of diameter $7 \mathrm{~mm}$. Chemical shifts were given in ppm from standard tetramethylsilane.

\subsection{Catalytic activity measurements}

Tert-butylation of ethylbenzene with $t$-butyl alcohol as the alkylating agent was carried out on a fixed-bed vertical down-flow reactor of internal diameter $2 \mathrm{~cm}$. About $0.5 \mathrm{~g}$ of the catalyst was placed in the reactor and supported on either side by a thin layer of quartz wool and ceramic beads. The reactor was heated to the requisite temperature using a temperature-programmed furnace. The catalyst was activated at $500{ }^{\circ} \mathrm{C}$ for $6 \mathrm{~h}$ in a controlled stream of air. The reactants were fed into the reactor using a syringe infusion pump. The products collected in the receiver flask were analyzed in a Shimadzu 17-A gas chromatograph equipped with a DB column and a flame ionization detector. The products were also identified using gas chromatography-mass spectrometry (Perkin Elmer Clarus 500). 


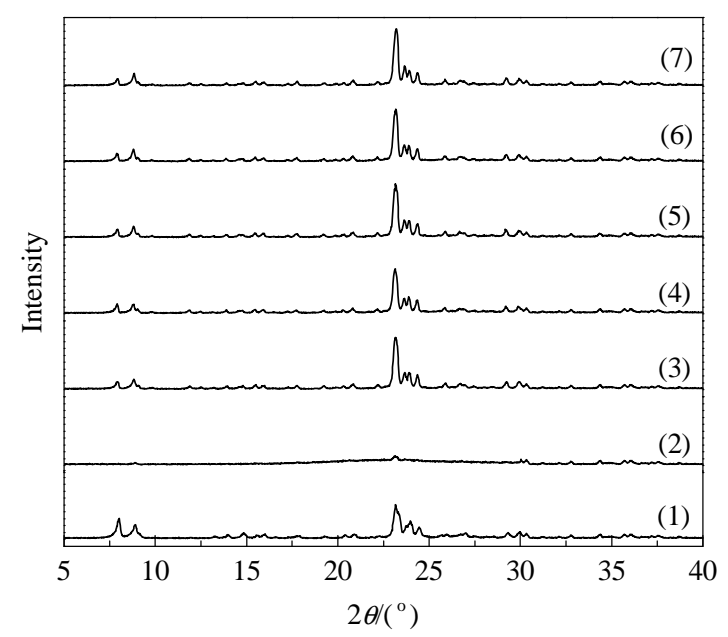

Fig. 1. XRD patterns of commercial ZSM-5(25) (1) and ZSM-5 synthesized with F/Si ratios of 0.3 (2), 0.6 (3), 1.0 (4), 1.3 (5), 1.6 (6), and 2.0 (7).

\section{Results and discussion}

\subsection{Catalyst characterization results}

\subsubsection{XRD}

The powder XRD patterns of ZSM-5 zeolites, synthesized in a fluoride medium with different fluoride contents, are presented in Fig. 1. The XRD pattern of commercial ZSM-5 is also presented in the same figure for comparison. The reflections in the XRD patterns of the synthesized samples were higher than those of the commercial sample. The fluoride medium was therefore proved to enhance the crystallinity of ZSM-5 [24,25]. The interactions of fluoride with both silicon and aluminum, facilitating their slow release for zeolite construction, are suggested as the main cause of the high crystallinity. Based on the intensity of the patterns, the optimum F/Si ratio for crystallization was in the range 1.0 to 1.6. A similar range was also reported by Louis and Kiwi-Minsker [24].

In fluoride-mediated synthesis, the acidity has been reported to be low as a result of formation of $\mathrm{AlF}_{X}$ species [25]. To suppress formation of such $\mathrm{AlF}_{x}$ species, a co-complexant to fluoride, namely phosphate, was used during the synthesis of

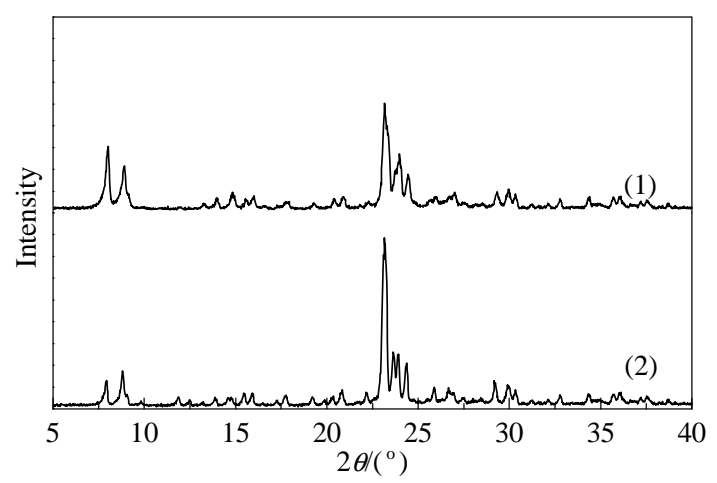

Fig. 2. XRD patterns of commercial ZSM-5(25) (1) and synthesized ZSM-5(25) (2).

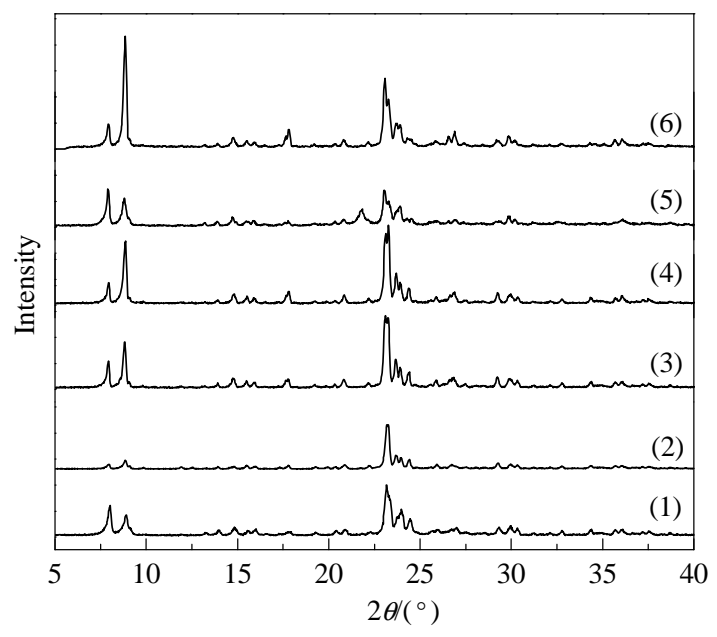

Fig. 3. XRD patterns of commercial ZSM-5(25) (1) and ZSM-5 synthesized with TEOS (2), HS silica (3), sodium silicate (4), AS silica (5), and fumed silica (6) as silicon sources.

ZSM-5(25). Its XRD pattern, shown in Fig. 2(2), displayed high crystallinity for all reflections.

The XRD patterns of ZSM-5 zeolites synthesized with different silicon sources are shown in Fig. 3. All the patterns showed the peaks characteristic of ZSM-5 reported in the literature $[26,27]$. The pattern derived from TEOS yielded more intense reflections than those from other silicon sources, therefore it was chosen for the bulk synthesis of ZSM-5 (Si/Al = 25 , 50, and 75). Ethanol, released from the hydrolysis of TEOS, reduced the dielectric constant of the medium, and enhanced the formation of highly crystalline zeolites. Sano et al. [28] reported the synthesis of large mordenite crystals in the presence of aliphatic alcohols. Slow dissolution of a gel and release of silicon and aluminum species enhanced the crystal size. The intensities of the peaks from (051) in Fig. 3(2), (3), and (4) were higher than those in Fig. 3(5) and (6). A low dielectric constant or sodium content in the medium was therefore suggested to play a characteristic role in enhancing crystallinity during synthesis. In addition, it was also seen to aid enhanced growth of (011). Therefore the sodium content, as well as the alcohol content, enhanced growth along the (051) and (011) directions compared with the other directions. Figure 3(6) shows more intense reflections than Fig. 3(5). The ammonium content of the synthesis gel with fumed silica was lower than that of the gel with AS silica, hence ammonium was also important in enhancing intensity. The synthesis gel with AS silica, which has a higher ammonium content than fumed silica, yielded low crystallinity ZSM-5 crystals, but a high ammonium content was seen to aid growth of $(-101)$ compared with (011). So, from this analysis, it was verified that a synthesis gel with a low dielectric constant, and a high sodium content or low ammonium content, yielded highly crystalline ZSM-5 zeolites.

The XRD patterns of the ZSM-5(25), (50), and (75) synthesized in a fluoride medium are presented in Fig. 4. The pattern of commercial ZSM-5 is also shown for comparison. Based on the intensities of the dominant XRD peaks, the crystallinities of all the ZSM-5 samples were calculated, and the values are pre- 


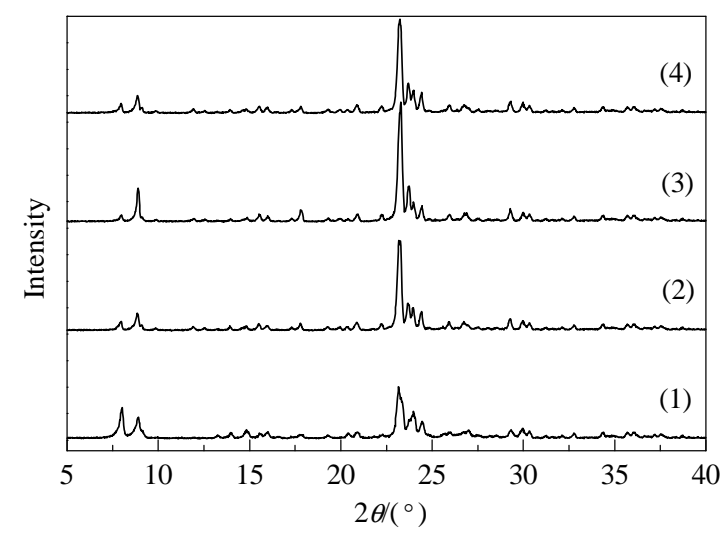

Fig. 4. XRD patterns of commercial ZSM-5(25) (1) and synthesized ZSM-5(25) (2), ZSM-5(50) (3), and ZSM-5(75) (4).

sented in Table 2. For the calculations, the crystallinity of the commercial ZSM-5 was taken as $100 \%$. As expected, the synthesized samples showed higher crystallinities than the commercial ZSM-5. This was also verified by SEM analysis, as discussed below.

\subsubsection{BET analysis}

The $\mathrm{N}_{2}$ adsorption-desorption isotherms of the synthesized zeolites are shown in Fig. 5. All the isotherms showed type I adsorption. The adsorption isotherms matched the desorption isotherms in all three cases. The knee portion of the ZSM-5(75) isotherm was lower than those of ZSM-5(25) and ZSM-5(50), indicating its lower surface area, as shown in Table 2. The isotherms also showed a lower micropore volume for ZSM-5(75) than for the others. The isotherms also showed a slightly higher surface area and pore volume for ZSM-5(50) than for ZSM-5(25) and ZSM-5(75).

\subsubsection{Potentiometric investigation of phosphate complexation of aluminum}

The $\mathrm{pH}$-volume curves for the titration of orthophosphoric acid versus potassium hydroxide, and orthophosphoric acid plus $\mathrm{Al}^{3+}$ versus potassium hydroxide, are shown in Fig. 6. In the titration of orthophosphoric acid, three buffer regions were identified, and the $\mathrm{p} K_{\mathrm{a}}$ values of $2.12\left(\mathrm{p} K_{\mathrm{a}} 1\right), 7.21\left(\mathrm{p} K_{\mathrm{a}} 2\right)$, and $12.30\left(\mathrm{p} K_{\mathrm{a}} 3\right)$ derived from them were comparable to those reported in the literature [29]. The titration curve of orthophosphoric acid plus $\mathrm{Al}^{3+}$ versus potassium hydroxide followed nearly the same trend as that of orthophosphoric acid versus potassium hydroxide, except that a fourth buffer region occurred at around $\mathrm{pH}$ 9.7, and there was a slight shift of the curve to lower $\mathrm{pH}$. This established the formation of a phos-

Table 2

Percentage crystallinities and BET results for ZSM- 5 zeolites.

\begin{tabular}{lccc}
\hline Catalyst & $\begin{array}{c}\text { Crystallinity } \\
(\%)\end{array}$ & $\begin{array}{c}\text { Surface area } \\
\left(\mathrm{m}^{2} / \mathrm{g}\right)\end{array}$ & $\begin{array}{c}\text { Pore volume } \\
\left(\mathrm{cm}^{3} / \mathrm{g}\right)\end{array}$ \\
\hline ZSM-5(25) & 100 & 430 & 0.163 \\
$\begin{array}{l}\text { (Commercial) } \\
\text { ZSM-5(25) }\end{array}$ & 117 & 750 & 0.259 \\
ZSM-5(50) & 124 & 790 & 0.280 \\
ZSM-5(75) & 120 & 634 & 0.214 \\
\hline
\end{tabular}

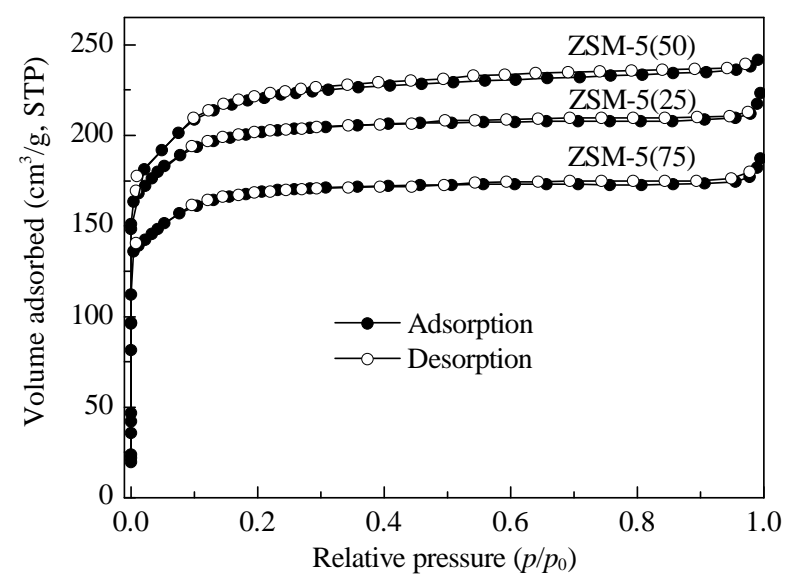

Fig. 5. $\mathrm{N}_{2}$ adsorption-desorption isotherms of the synthesized zeolites.

phate-aluminum complex.

As shown in Eqs. (1) and (2), complex formation between $\mathrm{Al}^{3+}$ and phosphate and hydrolysis of aluminum phosphate (Eq. 2) in the $\mathrm{pH}$ region between 2.20 and 3.35 released a larger number of protons than free orthophosphoric acid, and reduced the $\mathrm{pH}$.

$$
\mathrm{H}_{3} \mathrm{PO}_{4} \rightleftharpoons \mathrm{H}_{2} \mathrm{PO}_{4}^{-}+\mathrm{H}^{+}
$$

$$
\mathrm{Al}^{3+}+\mathrm{H}_{2} \mathrm{PO}_{4}^{-}+2 \mathrm{H}_{2} \mathrm{O} \rightleftharpoons\left[(\mathrm{OH})_{2} \mathrm{AlH}_{2} \mathrm{PO}_{4}\right]+2 \mathrm{H}^{+}
$$

When the $\mathrm{pH}$ was increased to 6.73-7.5, a second dissociation occurred (the second buffer region), according to Eqs. (3) and (4). If the complex $\left[(\mathrm{OH})_{2} \mathrm{AlH}_{2} \mathrm{PO}_{4}\right]$ has the same acidity as $\mathrm{H}_{2} \mathrm{PO}_{4}^{-}$, then the buffer region in the curve of orthophosphoric acid and that of orthophosphoric acid plus $\mathrm{Al}^{3+}$ coincide. However, a decrease in $\mathrm{pH}$ was observed for the latter compared with the former. The dissociation constant of $\left[(\mathrm{OH})_{2} \mathrm{AlH}_{2} \mathrm{PO}_{4}\right]$ may therefore be higher than that of $\mathrm{H}_{2} \mathrm{PO}_{4}$. Delocalization of the oxygen lone pair of the Al-O-P linkage in the aluminum vacant $3 p$ orbital resulted in a higher dissociation constant than that of $\mathrm{H}_{2} \mathrm{PO}_{4}^{-}$.

$$
\begin{aligned}
\mathrm{H}_{2} \mathrm{PO}_{4}^{-} & \rightleftharpoons \mathrm{HPO}_{4}^{2-}+\mathrm{H}^{+} \\
{\left[(\mathrm{OH})_{2} \mathrm{AlH}_{2} \mathrm{PO}_{4}\right] } & \rightleftharpoons\left[(\mathrm{OH})_{2} \mathrm{AlHPO}_{4}\right]^{-}+\mathrm{H}^{+}
\end{aligned}
$$

When the $\mathrm{pH}$ was increased to $9.60-10.19$, a third dissociation occurred (third buffer region), according to Eq. (5). This

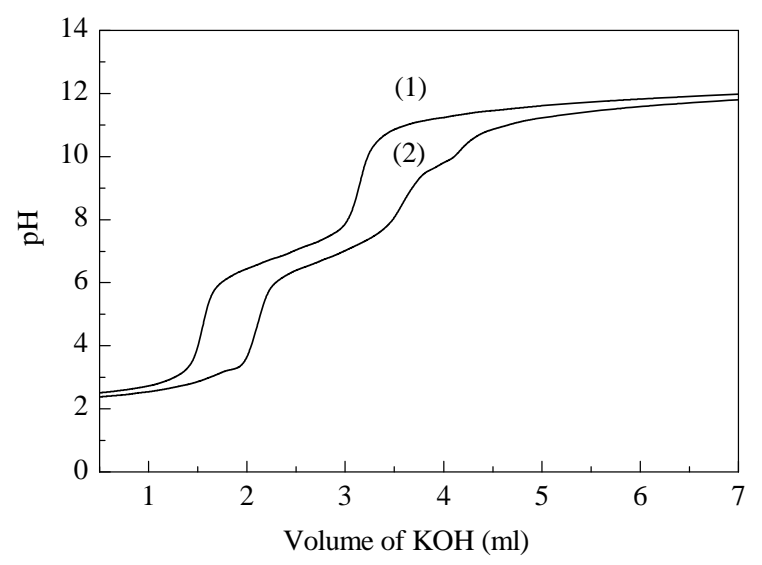

Fig. 6. Plot of pH versus volume of alkali for orthophosphoric acid versus potassium hydroxide (1) and orthophosphoric acid plus $\mathrm{Al}^{3+}$ versus potassium hydroxide (2). 

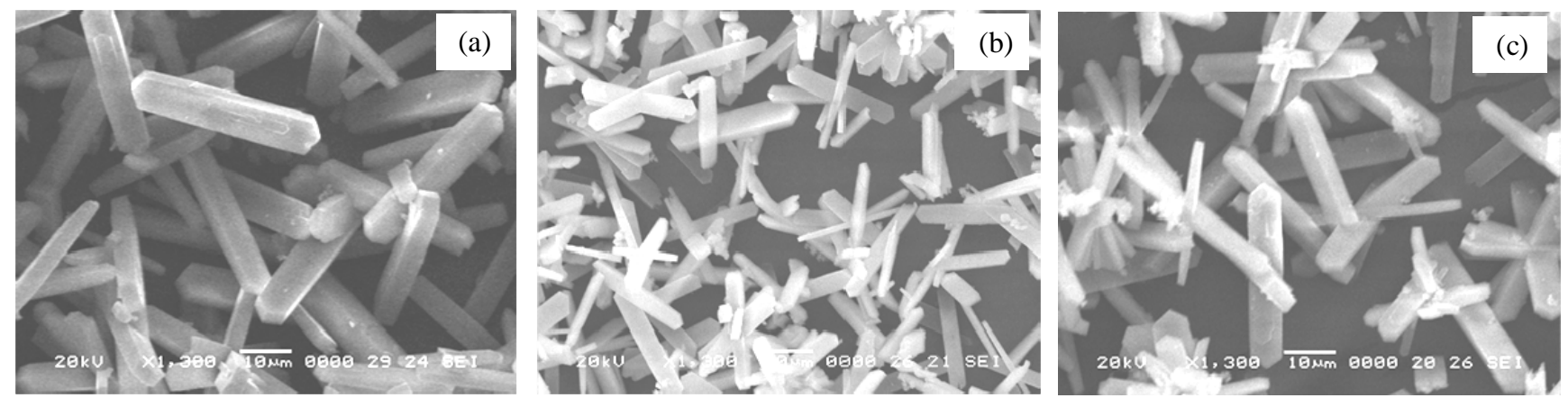

Fig. 7. SEM images of the synthesized ZSM-5(25) (a), ZSM-5(50) (b), and ZSM-5(75) (c).

buffer region did not exist in the titration of orthophosphoric acid itself, and was observed only in the titration of orthophosphoric acid plus $\mathrm{Al}^{3+}$. The dissociation of $\left[(\mathrm{OH})_{2} \mathrm{AlHPO}_{4}\right]^{-}$ species was confirmed by the formation of a clear solution. This was noted in the titration of $\mathrm{Al}^{3+}$ plus orthophosphoric acid, but not in the titration of orthophosphoric acid itself.

$$
\left[(\mathrm{OH})_{2} \mathrm{AlHPO}_{4}\right]^{-} \rightleftharpoons\left[\mathrm{O}^{-}(\mathrm{OH}) \mathrm{AlHPO}_{4}\right]^{2-}+\mathrm{H}^{+}
$$

If the $\mathrm{pH}$ was further increased to 11.30-12.22, a fourth dissociation occurred (fourth buffer region), as shown in Eq. (6). Here again, the buffer region for the titration of $\mathrm{Al}^{3+}$ plus orthophosphoric acid occurred at a lower $\mathrm{pH}$ than that of orthophosphoric acid. This again established complexation between $\mathrm{Al}^{3+}$ and phosphate.

$$
\left[\mathrm{O}^{-}(\mathrm{OH}) \mathrm{AlHPO}_{4}\right]^{2-} \rightleftharpoons\left[\mathrm{O}^{-}(\mathrm{OH}) \mathrm{AlPO}_{4}\right]^{3-}+\mathrm{H}^{+}
$$

These results established the formation of a stable phosphate complex with $\mathrm{Al}^{3+}$. Formation of such a complex is the reason for transportation of aluminum from the gel to the framework.

\subsubsection{SEM and EDS analyses}

The SEM images of ZSM-5(25), (50), and (75) are shown in Fig. 7. They show elongated prismatic crystals. The crystals of ZSM-5(75) were slightly smaller than those of the others. This verified that the $\mathrm{Si} / \mathrm{Al}$ ratio in the gel influences the crystal dimensions. As a gel with a high silica content takes longer to mineralize with fluoride, the crystallization time would also be longer than those for gels with low silica contents. This resulted in smaller crystal sizes for ZSM-5(75) than for the others. The crystal terraces in all the images were smooth, without any deposits. The tiny crystallites of ZSM-5(75) were the result of incomplete crystallization. Similar images were also obtained by Arichi and Louis [30].

To compare the Si/Al ratios of the synthesized zeolites with those of their mother liquids, EDS analyses were carried out. The results are given in Table 3 . The $\mathrm{Si} / \mathrm{Al}$ ratios of the synthe-

Table 3

Results of EDS analyses.

\begin{tabular}{lcccccccc}
\hline \multirow{2}{*}{ Catalyst } & \multicolumn{3}{c}{ Si/Al ratio } & & \multicolumn{5}{c}{ Atomic content by EDS (\%) } \\
\cline { 2 - 3 } \cline { 7 - 9 } & Mother liquid & By EDS & & Si & Al & 0 & P \\
\hline ZSM-5(25) & 25 & - & & - & - & - & - \\
(Commercial) & & & & & & & \\
ZSM-5(25) & 25 & 22.0 & & 14.7 & 0.7 & 84.6 & 0.0 \\
ZSM-5(50) & 50 & 38.0 & & 21.0 & 0.6 & 78.5 & 0.0 \\
ZSM-5(75) & 75 & 52.7 & & 20.0 & 0.4 & 79.5 & 0.0 \\
\hline
\end{tabular}

sized zeolites were slightly lower than those of the mother liquids. Complete transportation of aluminum from the mother liquid to the framework and a slightly reduced amount of silicon in the framework were therefore observed. In contrast to the previous report of formation of $\mathrm{AlF}_{x}$, which reduced the framework $\mathrm{Al}^{3+}$ content [25], the use of phosphate increased the content. These results therefore clearly established the influence of phosphate on the $\mathrm{AlF}_{x}$ equilibria and on the transportation of aluminum from the gel to the framework. The results also showed the absence of phosphate in the zeolite framework, even though the potentiometric titrations established bonding between aluminum and phosphate across the entire $\mathrm{pH}$ range. Phosphate remains in the coordination sphere of aluminum even if the latter is bonded to two silicate units, as shown in Scheme 1. When aluminum acquires a fourth coordination in the zeolite framework, phosphate will be immediately expelled, leaving aluminum in the trigonal planar state again. Tetrahedral coordination is therefore only allowed by chelating silicate units, and not by monodentate ligands such as phosphate.

\subsection{5. $\mathrm{NH}_{3}-\mathrm{TPD}$}

The $\mathrm{NH}_{3}$-TPD results are shown in Fig. 8. In the evaluation of zeolite acidity by $\mathrm{NH}_{3}$-TPD, three types of acid sites were suggested, based on the temperature range of ammonia desorption: weak acid sites, when the desorption occurs between 150 and $250{ }^{\circ} \mathrm{C}$, medium acid sites for desorption between 250 and $350{ }^{\circ} \mathrm{C}$, and strong acid sites for desorption between 350 and

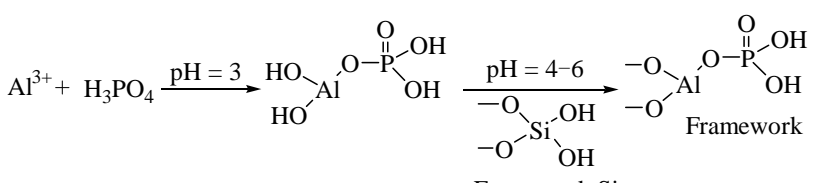

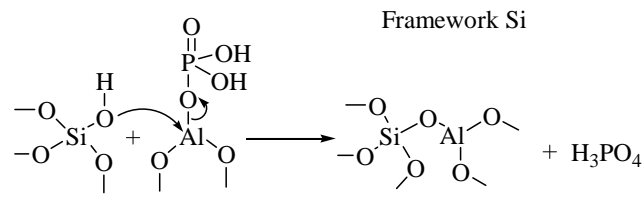

$$
\begin{aligned}
& \text { Framework Si Framework Al Framework }
\end{aligned}
$$

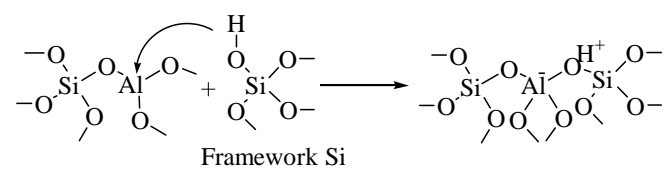

Scheme 1. Phosphate complexation of aluminum. 


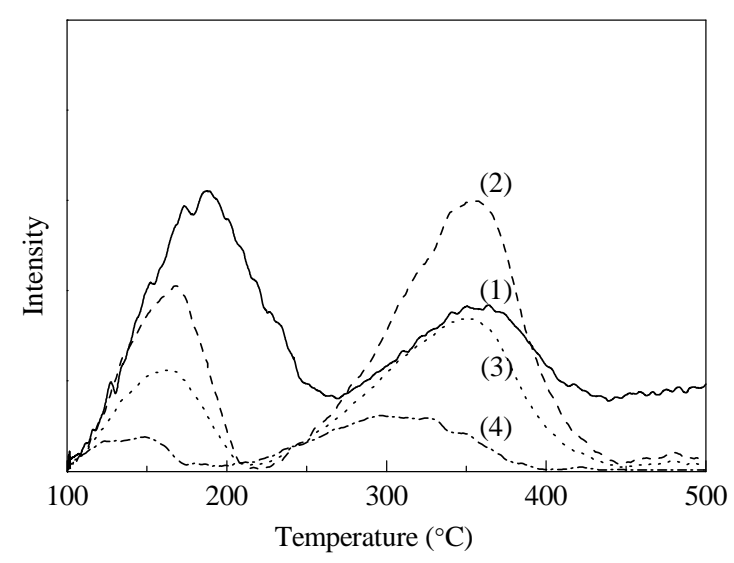

Fig. 8. $\mathrm{NH}_{3}$-TPD profiles of commercial ZSM-5(25) (1) and the synthesized ZSM-5(25) (2), ZSM-5(50) (3), and ZSM-5(75) (4).

$450{ }^{\circ} \mathrm{C}$ [31-33]. The peak between 100 and $210^{\circ} \mathrm{C}$ for the weak acid sites was clearly resolved for the synthesized zeolites, but those of the medium and strong acid sites between 210 and $450{ }^{\circ} \mathrm{C}$ overlapped significantly. The quantity of weak acid sites was lower than those of medium and strong acid sites. An additional role of the fluoride medium is therefore to create larger numbers of acid sites in the channel intersections, the regions for strong acid sites, than along the channels, the regions for weak acid sites. It has also been reported that in zeolites, 75\% of total acid sites were present in channel intersections and the rest along the channels [34]. This was verified for the synthesized zeolites in this study, because there were more medium and strong acid sites than weak acid sites. The $\mathrm{NH}_{3}$-TPD profiles also illustrated that with increasing $\mathrm{Si} / \mathrm{Al}$ ratio, the quantity of strong acid sites, corresponding to desorption between 350 and $450{ }^{\circ} \mathrm{C}$, decreased. In addition, the desorption shifted from 450 to $400{ }^{\circ} \mathrm{C}$ with increasing $\mathrm{Si} / \mathrm{Al}$ ratio, and this was clearly seen for ZSM-5(75). It is difficult to understand why this was not also observed for ZSM-5(25) and (50), for which only the densities were affected, not the strengths. The $\mathrm{Si} / \mathrm{Al}$ ratio alone is therefore not the controlling factor for the strengths of the acid sites; the densities of acid sites located in the channel intersections are also important. If the $\mathrm{Si} / \mathrm{Al}$ ratio of the zeolite is above 50, the acid sites are weak/medium, irrespective of their location, therefore the higher the $\mathrm{Si} / \mathrm{Al}$ ratio (particularly above 50), the fewer the number of acid sites, even in the channel intersections, and the greater the decrease in the strengths of such sites. Such a decrease was also noted for the weak acid sites; again, this was clearly observed for ZSM-5(75). So, with increasing Si/Al ratio, the acid sites are located far off, and they are weaker than those of zeolites with lower Si/Al ratios. Again, the weak acid sites of ZSM-5(25) and (50) showed only a decrease in the density, not in the strength, unlike the medium and strong acid sites. Diffuse reflectance infrared Fourier transform (DRIFT) is a technique used to study acidity, using pyridine and other bulky amines. Bulky amines are important in determining the external surface acidity, which confirm the crystallinity, but DRIFT facilities were not available.

The results for the commercial ZSM-5(25) zeolite are also shown in Fig. 8. The intensities of the peaks from the medium and strong acid sites were lower than those for the synthesized ZSM-5(25). Here, too, the peaks from the medium and strong acid sites overlapped, but desorption of ammonia extended above $400{ }^{\circ} \mathrm{C}$. The strong acid sites of the commercial catalyst might therefore be stronger than those of the synthesized ZSM-5(25) and (50) catalysts. This indicates a high density of acid sites in the channel intersections in the commercial catalyst. The absence of desorption was the result of adsorption-desorption equilibrium of ammonia. The desorption peak from the weak acid sites was more intense than those of the synthesized zeolites. The desorption also extended above 200 ${ }^{\circ} \mathrm{C}$, hence these acid sites were more acidic than those of the synthesized zeolites. As the weak acid sites are located along the channels, the density might be high enough to increase their strength. So, it was expected that the commercial zeolite might be more active than the synthesized zeolites in the tert-butylation of ethylbenzene.

\subsection{6. ${ }^{27}$ Al MAS-NMR and ${ }^{29}$ Si MAS-NMR}

The ${ }^{27} \mathrm{Al}$ MAS-NMR and ${ }^{29}$ Si MAS-NMR spectra of ZSM-5(25) is shown in Fig. 9. In Fig. 9(a), the intense sharp peak centered at $\delta=52$ arose from the tetrahedrally coordinated framework aluminum [35]. As there was no peak close to $\delta=0$, non-framework alumina was proved to be absent. Dislodging of aluminum from the framework during calcination was therefore ruled out. The result also confirmed the thermal stability of ZSM-5 synthesized in a fluoride medium.

The peak at $\delta=-106$ in Fig. 9(b) was from $\mathrm{Q}^{3}$ species [Si$\left.(\mathrm{OSi})_{3}(\mathrm{OAl})\right]$ and that at $\delta=-112$ was from $\mathrm{Q}^{4}$ species [Si $(\mathrm{OSi})_{4}$ ] $[17,36]$. As there was no peak below $\delta=-106$ (close to $\delta=$ $-103)$, there were not significant numbers of defective Si-OH groups. This is important evidence of high crystallinity of the zeolite, as discussed above.

\subsection{Catalytic studies}

Vapor-phase tert-butylation of ethylbenzene with $t$-butyl alcohol was studied over commercial ZSM-5(25) and the synthesized ZSM-5(25), ZSM-5(50), and ZSM-5(75) between 200 and $400{ }^{\circ} \mathrm{C}$. The reaction parameters were optimized for maximum ethylbenzene conversion and high selectivity for 4- $t$-BEB. The effects of temperature, feed ratio, weight hourly space ve-
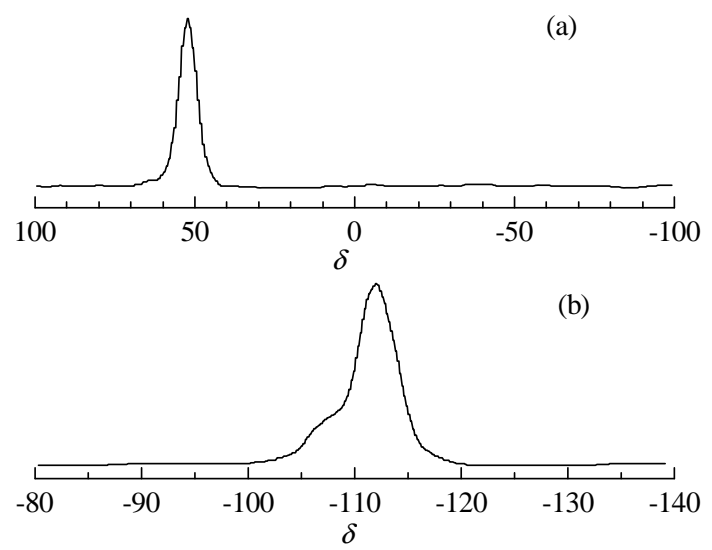

Fig. 9. ${ }^{27} \mathrm{Al}$ MAS-NMR (a) and ${ }^{29} \mathrm{Si}$ MAS-NMR (b) spectra of ZSM-5(25). 
Table 4

Effects of temperature on ethylbenzene conversion and product selectivity.

\begin{tabular}{|c|c|c|c|c|c|c|c|c|c|}
\hline \multirow{2}{*}{ Catalyst } & \multirow{2}{*}{$\begin{array}{c}\text { Temperature } \\
\left({ }^{\circ} \mathrm{C}\right)\end{array}$} & \multirow{2}{*}{$\begin{array}{l}\text { Ethylbenzene } \\
\text { conversion (\%) }\end{array}$} & \multicolumn{7}{|c|}{ Selectivity (\%) } \\
\hline & & & 1,2-DEB & 1,3-DEB & 1,4-DEB & 3-t-BEB & 4-t-BEB & 4-t-BVB & Benzene \\
\hline ZSM-5(25) & 200 & 39.1 & 4.3 & 2.2 & 6.8 & 10.0 & 74.1 & - & 2.6 \\
\hline \multirow[t]{4}{*}{ (Commercial) } & 250 & 44.3 & 3.0 & 1.1 & 8.3 & 19.8 & 64.0 & - & 3.8 \\
\hline & 300 & 55.9 & 1.6 & 2.6 & 11.9 & 17.2 & 61.3 & - & 5.4 \\
\hline & 350 & 49.4 & 1.5 & 3.9 & 12.0 & 18.8 & 22.2 & 29.5 & 12.1 \\
\hline & 400 & 32.2 & 1.4 & 6.0 & 11.7 & 22.9 & 5.2 & 27.9 & 24.9 \\
\hline \multirow[t]{5}{*}{ ZSM-5(25) } & 200 & 33.5 & - & - & - & 5.1 & 94.9 & - & - \\
\hline & 250 & 41.7 & - & - & - & 6.7 & 93.3 & - & - \\
\hline & 300 & 49.3 & - & - & - & 7.6 & 92.4 & - & - \\
\hline & 350 & 44.1 & - & - & - & 9.0 & 91.0 & - & - \\
\hline & 400 & 28.0 & - & - & - & 11.3 & 88.7 & - & - \\
\hline \multirow[t]{5}{*}{ ZSM-5(50) } & 200 & 30.3 & - & - & - & 7.2 & 92.8 & - & - \\
\hline & 250 & 38.2 & - & - & - & 8.3 & 91.7 & - & - \\
\hline & 300 & 41.6 & - & - & - & 10.1 & 89.9 & - & - \\
\hline & 350 & 39.9 & - & - & - & 13.2 & 86.8 & - & - \\
\hline & 400 & 30.4 & 1.3 & 4.2 & 2.0 & 14.9 & 73.6 & - & 4.0 \\
\hline \multirow[t]{5}{*}{ ZSM-5(75) } & 200 & 25.3 & - & - & - & 8.3 & 91.7 & - & - \\
\hline & 250 & 31.7 & - & - & - & 10.4 & 89.6 & - & - \\
\hline & 300 & 38.3 & - & - & - & 12.3 & 87.7 & - & - \\
\hline & 350 & 36.5 & 2.2 & 5.1 & 4.2 & 14.5 & 69.5 & - & 4.5 \\
\hline & 400 & 33.8 & 3.2 & 6.9 & 5.1 & 17.8 & 59.7 & - & 7.3 \\
\hline
\end{tabular}

Reaction conditions: feed ratio ethylbenzene:tert-butyl alcohol $=1: 1 ;$ WHSV $=1.65 \mathrm{~h}^{-1}$.

locity (WHSV), and time-on-stream on conversion and product selectivity were examined; the results are discussed below.

\subsubsection{Effects of temperature}

tert-Butylation of ethylbenzene with $t$-butyl alcohol was carried out over commercial ZSM-5(25) at 200, 250, 300, 350, and $400{ }^{\circ} \mathrm{C}$. The products were 1,2-diethylbenzene (DEB), 1,3-DEB, 1,4-DEB, 3- $t$-BEB, 4- $t$-BEB, 4- $t$-BVB, and benzene. The conversions of ethylbenzene and the selectivities for different products are presented in Table 4 . The conversion increased from 200 to $300{ }^{\circ} \mathrm{C}$, but decreased at 350 and $400{ }^{\circ} \mathrm{C}$ as a result of blocking of active sites by polybutene [37] and/or coke. Coke was also observed between 200 and $300^{\circ} \mathrm{C}$, but to a lesser extent than between 350 and $400{ }^{\circ} \mathrm{C}$. A plausible pathway for tert-butylation of ethylbenzene is shown in Scheme 2. $t$-Butyl alcohol is chemisorbed on the Brönsted acid site of zeolites to form $t$-butyl cations. The electrophilic reaction between ethylbenzene and $t$-butyl cations yields 4-t-BEB.

In addition to tert-butylation of ethylbenzene, disproportionation of ethylbenzene was also observed, but was minimal. The disproportionation of ethylbenzene can occur as shown in Scheme 3. Ethylbenzene is chemisorbed on the Brönsted acid<smiles>CCc1ccccc1</smiles>

Scheme 2. Formation of 4-t-BEB.

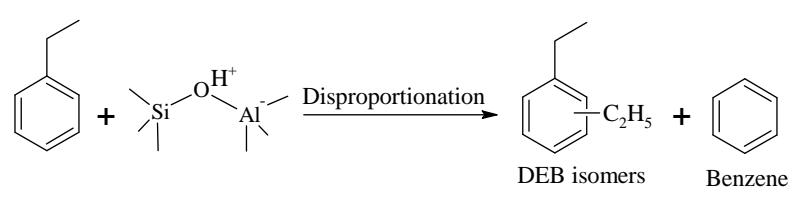

Scheme 3. Disproportionation of ethylbenzene. sites of ZSM-5 to form benzene and ethyl cations. Electrophilic reaction between ethyl cations and ethylbenzene yields diethylbenzene isomers, i.e., 1,2-DEB, 1,3-DEB, and 1,4-DEB. The ethyl cations formed by de-ethylation of ethylbenzene attack at the ortho- and para-positions of ethylbenzene to form 1,2-DEB and 1,4-DEB, respectively. As the meta-position of ethylbenzene is not favored for electrophilic attack, 1,3-DEB has to be formed by isomerization of 1,4-DEB or 1,2-DEB on the external surface of the zeolite.

Since the kinetic diameter of 1,2 -DEB is $0.68 \mathrm{~nm}$, it can be formed in the channel intersections, but it cannot diffuse out of the crystals. 1,4-DEB can be formed either in the channel intersections or along the channels, and it can freely diffuse out, as its kinetic diameter is $0.58 \mathrm{~nm}$. 1,3-DEB, with a kinetic diameter of $0.68 \mathrm{~nm}$, can be formed by isomerization of 1,4-DEB or 1,2-DEB on the external surfaces or in the channel intersections. The selectivity for 1,2-DEB was very low, as it was formed on the external surfaces, and some of it isomerized to 1,3-DEB. The slight decrease in selectivity for 1,2-DEB from 200 to $400{ }^{\circ} \mathrm{C}$ was the result of increased steric hindrance for substitution at the ortho position as a result of free rotation of the ethyl group about the $\mathrm{C}-\mathrm{C}$ bond. Such free rotation of alkyl groups in alkyl aromatics has been reported previously [38]. At low temperatures, the rotation would be slow, but at high temperatures it would be rapid, thus significantly suppressing substitution at both ortho positions. The formation of free benzene also supported disproportionation of ethylbenzene. The<smiles>CCc1ccc(C(C)(C)C)cc1</smiles>

Scheme 4. Isomerization of 4-t-BEB to 3-t-BEB. 


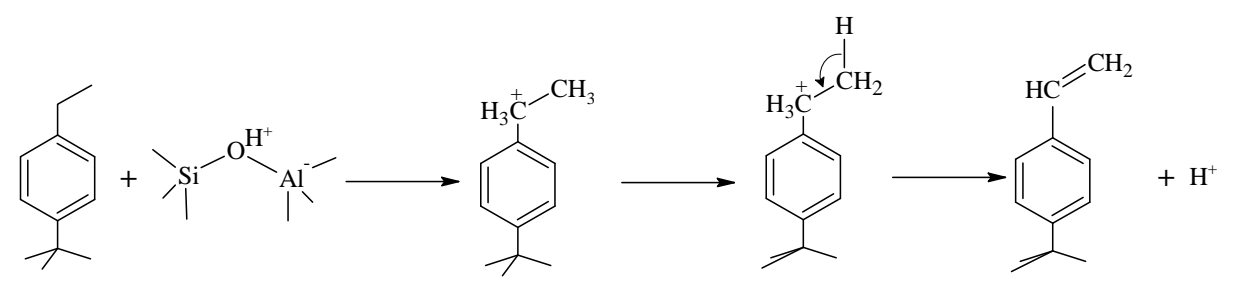

Scheme 5. Carbenium/carbonium ion mechanism.

selectivity for 4-t-BEB decreased with increasing temperature as a result of isomerization to form 3-t-BEB.

The isomerization of 4- $t$-BEB proceeds as shown in Scheme 4. 4-t-BEB is chemisorbed on the Brönsted acid sites of ZSM-5. Protonation of 4- $t$-BEB occurs on the carbon that carries the $t$-butyl group. Reorganization of bonds results in the migration of the $t$-butyl group to the meta position to form 3-t-BEB. Such a mechanism has already been reported [22]. The meta isomers are thermodynamically more stable than the para isomers, and this becomes the driving force for isomerization, so the selectivity for 3-t-BEB increases with increasing temperature. The molecular size of $3-t$-BEB $(0.68 \mathrm{~nm})$ is higher than the zeolite pore size. Isomerization of $4-t$-BEB to $3-t$-BEB can therefore only occur on the external surface of the zeolite. An unexpected product is $4-t-B V B$, so there is dehydrogenation of the ethyl group of 4-t-BEB to 4-t-BVB. Such dehydrogenation has been reported to result from the presence of non-framework alumina in mesoporous AlMCM-41 [22], so the catalyst might have non-framework alumina. In the absence of it, dehydrogenation is suggested to occur by a carbenium/carbonium ion mechanism (Scheme 5). A proton is transferred to the methylene group of 4-t-BEB to form a pentacoordinated transition state. This decomposes to form a carbenium ion, which subsequently releases an $\alpha$-hydrogen to form 4-t-BVB. However, such dehydrogenation was not observed for ethylbenzene, as styrene was not observed. Hence, the para $t$-butyl group of 4-t-BEB might activate formation of 4-t-BVB. Since the $t$-butyl group is inductively electron-repelling, it enhances the electronic cloud on the methylene group and facilitates proton transfer to the methylene from the zeolite.

The same reaction was also studied over synthesized ZSM-5(25), ZSM-5(50), and ZSM-5(75). The results are also presented in Table 4. These catalysts showed variations in the conversions of ethylbenzene similar to those of the commercial catalyst. The conversion increased from 200 to $300{ }^{\circ} \mathrm{C}$ and decreased thereafter. ZSM-5(25) showed a higher conversion than others as a result of a higher density of acid sites. Although the acidity of ZSM-5(50) was 50\% less than that of ZSM-5(25), the conversion at $300{ }^{\circ} \mathrm{C}$ was not $50 \%$ lower. This is because of slow diffusion of reactants along the channels in ZSM-5(50) as a result of its higher hydrophobicity. An important observation in the reactions over ZSM-5 catalysts synthesized in a fluoride medium was the complete absence of dehydrogenation and disproportionation at $300{ }^{\circ} \mathrm{C}$. Disproportionation of ethylbenzene can occur either inside or outside the pores, but acid sites must be available. Since $t$-butyl alcohol is better chemisorbed than ethylbenzene on Brönsted acid sites, disproportionation of ethylbenzene is avoided over all the catalysts. The selectivity for 3-t-BEB increased with increasing temperature over all the catalysts. ZSM-5(75) showed a slightly higher selectivity for 3- $t$-BEB than the others, but a lower selectivity than commercial ZSM-5. Since it is more hydrophobic than the others, it can better retain 4- $t$-BEB and promote isomerization on the external surfaces. Although commercial ZSM-5 is more hydrophilic than the others, its strong acidity and low crystallinity result in high selectivity for 3-t-BEB. The optimum temperature was 300 ${ }^{\circ} \mathrm{C}$, based on high conversion, and ZSM-5(25) performed better than the others.

The synthesized zeolite ZSM-5(25) showed lower conversion than the commercial ZSM-5, although both have the same $\mathrm{Si} / \mathrm{Al}$ ratio. This is because the strong acid sites of the commercial zeolite are of higher strength than those of the synthesized zeolite.

\subsubsection{Effects of WHSV}

Since the isomerization of $4-t$-BEB occurs on the few Brönsted acid sites present on the external surface, it could be avoided, or at least minimized, by increasing the WHSV. The results of the effects of WHSV on ethylbenzene conversion and product selectivity are presented in Table 5. The conversion decreased with increasing WHSV. As expected, the isomerization activity decreased with increasing WHSV, thus confirming our deductions. The optimum WHSV was $1.65 \mathrm{~h}^{-1}$. The selectivity for 4-t-BEB at $6.61 \mathrm{~h}^{-1}$ was higher than those at the other WHSVs, but the conversion was low, so it was not the optimum value.

\subsubsection{Effects of feed ratio}

The feed ratio was altered to study its influence on ethylbenzene conversion and product selectivity; the results are presented in Table 6 . The conversion decreased with increasing $t$-butyl alcohol content in the feed. The ZSM-5 channels could be filled with large numbers of $t$-butyl cations, and these could offer high steric hindrance to diffusion of tert-butylated ethylbenzene. A high alcohol content in the feed, particularly above a feed ratio of $1: 1$, might therefore not be

\section{Table 5}

Effects of WHSV on ethylbenzene conversion and product selectivity over ZSM-5(25).

\begin{tabular}{ccccc}
\hline \multirow{2}{*}{$\begin{array}{c}\text { Feed rate } \\
(\mathrm{ml} / \mathrm{h})\end{array}$} & $\begin{array}{c}\text { WHSV } \\
\left(\mathrm{h}^{-1}\right)\end{array}$ & $\begin{array}{c}\text { Ethylbenzene } \\
\text { conversion }(\%)\end{array}$ & \multicolumn{2}{c}{ Selectivity (\%) } \\
\cline { 4 - 5 } 1 & 1.65 & 49.3 & 7.6 & 92.4 \\
2 & 3.31 & 43.5 & 5.7 & 94.3 \\
3 & 4.96 & 40.2 & 2.5 & 97.5 \\
4 & 6.61 & 30.9 & 1.5 & 98.5 \\
\hline
\end{tabular}

Reaction conditions: temperature $300^{\circ} \mathrm{C}$, feed ratio 1:1. 
Table 6

Effects of feed ratio on ethylbenzene conversion and product selectivity over ZSM-5(25).

\begin{tabular}{ccccc}
\hline \multirow{2}{*}{ Feed ratio } & WHSV & Ethylbenzene & \multicolumn{2}{c}{ Selectivity (\%) } \\
\cline { 4 - 5 } & $\left(\mathrm{h}^{-1}\right)$ & conversion (\%) & 3-t-BEB & 4-t-BEB \\
\hline $1: 1$ & 1.65 & 49.3 & 7.6 & 92.4 \\
$1: 2$ & 1.62 & 42.7 & 5.5 & 94.5 \\
$1: 3$ & 1.61 & 36.2 & 3.9 & 96.1 \\
$2: 1$ & 1.68 & 51.5 & 6.8 & 93.2 \\
$3: 1$ & 1.69 & 48.8 & 9.2 & 90.8 \\
\hline
\end{tabular}

Reaction conditions: temperature $300^{\circ} \mathrm{C}$, feed rate $1 \mathrm{ml} / \mathrm{h}$.

conducive to high conversion. However, when the ratio was changed to $2: 1$, the conversion increased as there may not be many free $t$-butyl cations along the channels to offer hindrance to diffusion of 4-t-BEB. In other words, close adsorption of $t$-butyl cations prevents a high rate of diffusion of 4- $t$-BEB. Hence, optimizing the ethylbenzene content in the feed may be better than other alternatives for enhancing conversion; 2:1 was chosen as the optimum feed ratio. Although a large crystal size is generally good for high para selectivity, as discussed in the introduction, the present reaction does not depend on the shape-selective features of zeolites. As the ortho product is avoided as a result of steric hindrance, and the meta product is kinetically unfavorable, the reaction gives the para product preferentially. Even if the meta product is formed in the channel intersections, it cannot diffuse out of the pores. The meta product can therefore only be formed by isomerization of the para product on the external surface. If the external surface carries few weak acid sites, these sites can be blocked by post-modification for complete suppression of isomerization. Since ZSM-5 synthesized in a fluoride medium was highly crystalline, its isomerization activity was minimum. In addition, disproportionation was also greatly suppressed.

\subsubsection{Effects of time-on-stream}

The effects of time-on-stream on ethylbenzene conversion and product selectivity were studied at $300^{\circ} \mathrm{C}$ with a feed ratio of 2:1; the results are shown in Fig. 10. The conversion decreased with increasing time-on-stream, but the decrease was not rapid. This was because of the medium pore size, which

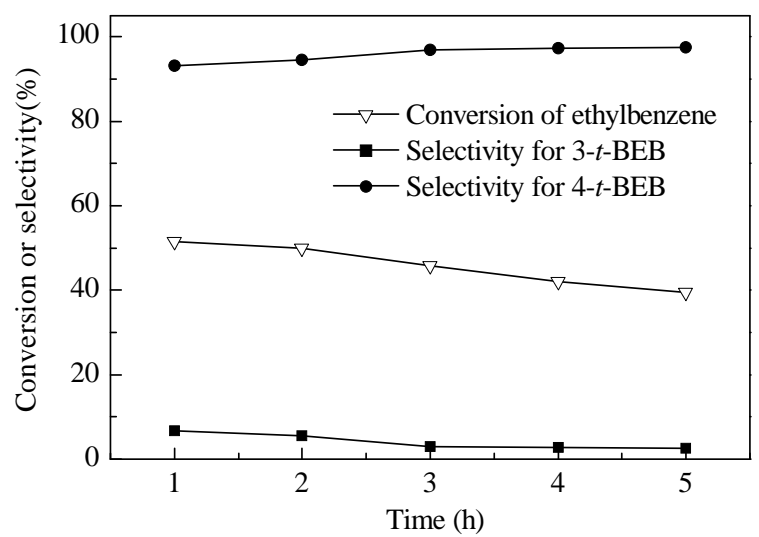

Fig. 10. Effects of time-on-stream on ethylbenzene conversion and product selectivity over ZSM-5(25). does not provide mush space for coke formation inside the pores. The selectivity for 3-t-BEB decreased slightly with increasing time-on-stream as a result of blocking of the external surface acid sites by coke. As coke formation is very much favored on such external acid sites, these sites were gradually deactivated and isomerization also gradually decreased. The decrease in the selectivity for $3-t$-BEB and the increase in the selectivity for 4- $t$-BEB confirmed that the latter is the precursor of the former. In addition, the deactivation of external acid sites may be more rapid than deactivation of sites lying inside the channels, as the medium pore size may not encourage coke formation, which requires a lot of space [15], as stated above. 2-t-BEB was not obtained during the entire period of time-on-stream. The time-on-stream study illustrates that if the few external acid sites are completely blocked by coke formation, the catalyst can give $100 \%$ selectivity for $4-t$-BEB.

\section{Conclusions}

ZSM-5 synthesized in a fluoride medium is better than other zeolites for para-selective alkylation of aromatics or alkyl aromatics, as trans alkylation, disproportionation, and isomerization are suppressed. The fluoride medium provides large ZSM-5 crystals of high crystallinity, significantly improving the para selectivity of the catalyst. In ZSM-5, coke formation is also suppressed, because of its medium pore size. The number of external acid sites is minimized because of the high crystallinity. Even if there are few external acid sites, their activity for isomerization is rapidly lost as a result of coke deposition. By blocking such acid sites by simple post-modification, it is possible to ensure $100 \%$ para selectivity. A fluoride medium is therefore better than an alkaline medium for the commercial production of defect-free highly crystalline para-selective ZSM-5 catalysts.

\section{References}

[1] Ichioka R, Yamakawa S, Okino H, Kato H, Iwayama K, Konta H, Kitamura A. US Patent 6040 490. 2000

[2] Zuo X, Niu F, Snavely K, Subramaniam B, Busch D H. Green Chem, 2010, 12: 260

[3] Chavan S A, Srinivas D, Ratnasamy P. J Catal, 2001, 204: 409

[4] Chu C C. US Patent 4496662.1985

[5] Burress G T. US Patent 4565 899. 1986

[6] Kaeding W W, Yannich P J, Klosek J M, Young L B. EP Patent 0217492.1987

[7] Drobny J G. Handbook of Thermoplastic Elastomers. 1st Ed. New York: William Andrew Inc, 2007. 175

[8] Danilina N, Payrer E L, van Bokhoven J A. Chem Commun, 2010, 46: 1509

[9] Wise J J. US Patent 3251 897. 1966

[10] Haag W O, Lago R M, Weisz P B. Faraday Discuss Chem Soc, 1981, 72: 317

[11] Olson D H, Haag W O. ACS Symp Ser, 1984, 248: 275

[12] Halgeri A B. Bull Catal Soc India, 2003, 2: 184

[13] Kim J H, Namba S, Yashima T. Zeolites, 1991, 11: 59

[14] Kim J H, Namba S, Yashima T. Appl Catal A, 1993, 100: 27

[15] Chen N Y, Garwood W E, Dwyer F G. Shape Selective Catalysis in Industrial Applications. 1st Ed. New York: Dekker, 1989. 26 
[16] Guth J L, Kessler H, Higel J M, Lamblin J M, Patarin J, Seive A, Chezeau J M, Wey R. ACS Symp Ser, 1989, 398: 176

[17] Axon S A, Klinowski J. Appl Catal A, 1994, 111: 29

[18] Kessler H, Patarin J, Schott-Darie C. Stud Surf Sci Catal, 1994, 85: 75

[19] Nayak V S, Riekert L. Appl Catal, 1986, 23: 403

[20] Paparatto G, Moretti E, Leofanti G, Gatti F. J Catal, 1987, 105: 227

[21] Arsenova-Härtel N, Bludau H, Schumacher R, Haag W O, Karge H G, Brunner E, Wild U.J Catal, 2000, 191: 326

[22] Umamaheswari V, Palanichamy M, Arabindoo B, Murugesan V. Proc Indian Acad Sci Chem Sci, 2002, 114: 203

[23] Bidart A M F, Borges A P S, Chagas H C, Nogueira L, Lachter E R, Mota C J A. J Braz Chem Soc, 2006, 17: 758

[24] Louis B, Kiwi-Minsker L. Microporous Mesoporous Mater, 2004, 74: 171

[25] Gougeon R D, Brouwer E B, Bodart P R, Delmotte L, Marichal C, Chezeau J M, Harris R K. J Phys Chem B, 2001, 105: 12249

[26] Treacy M M J, Higgins J B. Collection of Simulated XRD Powder Patterns for Zeolites. 4th Ed (Rev). Amsterdam: Elsevier, 2001. 239

[27] Woolery G L, Kuehl G H, Timken H C, Chester A W, Vartuli J C. Zeo- lites, 1997, 19: 288

[28] Sano T, Wakabayashi S, Oumi Y, Uozumi T. Microporous Mesoporous Mater, 2001, 46: 67

[29] Jeffery G H, Bassett J, Mendham J, Denney R C. Vogel's Textbook of Quantitative Chemical Analysis. 5th Ed. UK: Longman, 1989. 833

[30] Arichi J, Louis B. Cryst Growth Des, 2008, 8: 3999

[31] Kim J H, Park M J, Kim S J, Joo O S, Jung K D. Appl Catal A, 2004, 264: 37

[32] Vishwanathan V, Jun K W, Kim J W, Roh H S. Appl Catal A, 2004, 276: 251

[33] Kim S D, Baek S C, Lee Y J, Jun K W, Kim M J, Yoo I S. Appl Catal A, 2006, 309: 139

[34] Bortnovsky O, Sazama P, Wichterlova B. Appl Catal A, 2005, 287: 203

[35] Seiler M, Wang W, Hunger M. J Phys Chem B, 2001, 105: 8143

[36] Grieken R V, Sotelo J L, Menéndez J M, Melero J A. Microporous Mesoporous Mater, 2000, 39: 135

[37] Liu Z, Moreau P, Fajula F. Appl Catal A, 1997, 159: 305

[38] Schaefer T, Chan W K, Sebastian R, Schurko R, Hruska F E. Can J Chem, 1994, 72: 1972

\section{Graphical Abstract}

Chin. J. Catal., 2013, 34: 294-304 doi: 10.1016/S1872-2067(11)60482-8

\section{Effects of crystallinity of ZSM-5 zeolite on para-selective tert-butylation of ethylbenzene}

PUSHPARAJ Hemalatha, MANI Ganesh, MUTHIAHPILLAI Palanichamy, VELAYUTHAM Murugesan, PARK Yong-Ki, CHOI Won Choon, JANG Hyun Tae*

Hanseo University, South Korea; Anna University, India; Korea Research Institute of Chemical Technology, South Korea

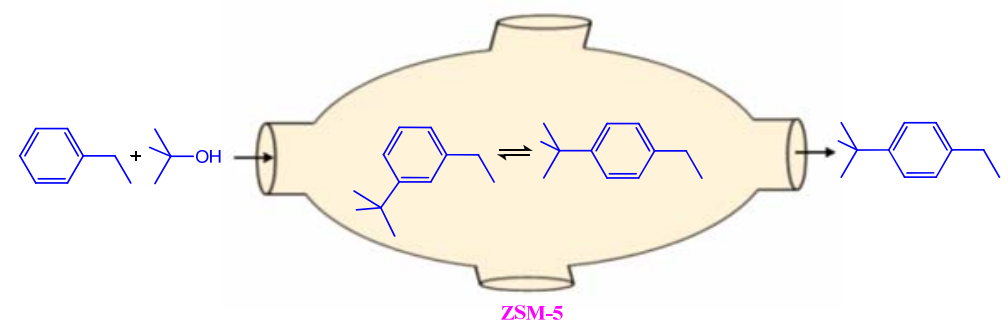

A fluoride medium offers defect-free, highly crystalline ZSM-5 crystals. High crystallinity confers high para selectivity (> 90\%) in tert-butylation of ethylbenzene. A fluoride medium is better than an alkaline medium for the commercial production of para-selective ZSM-5 catalysts. 